\title{
Thermal stability and degradation of selected poly (alkyl methacrylates) used in the polymer industry
}

\author{
Zbigniew Czech • Kowalczyk Agnieszka • \\ Paulina Ragańska • Adrian Antosik
}

Received: 6 June 2014/ Accepted: 4 November 2014/Published online: 4 December 2014

(C) The Author(s) 2014. This article is published with open access at Springerlink.com

\begin{abstract}
This article describes our results for the thermal stability and thermal degradation of poly(alkyl methacrylates) based on selected methacrylate monomers, namely methyl methacrylate, butyl methacrylate, and 2-ethylhexyl methacrylate, which are used in the polymer industry in the manufacture of construction polymers, polymeric films, and a wide range of adhesives. Quantitative analyses of the thermal degradation products of poly(methyl methacrylate), poly(butyl methacrylate), and poly(2-ethylhexyl methacrylate) were performed, principally with pyrolysisgas chromatography at temperatures between 200 and $400{ }^{\circ} \mathrm{C}$. The dependencies of the thermal stabilities of the tested poly(alkyl methacrylates) on their molecular weight were investigated. The major degradation products are the corresponding methacrylate monomers; the other thermal degradation by-products are carbon dioxide, carbon monoxide, methane, ethane, methanol, ethanol, and 1-propanol.
\end{abstract}

Keywords Synthesis - Poly(alkyl methacrylate) ·

Thermal degradation - Pyrolysis - Methyl methacrylate .

Butyl methacrylate $\cdot$ 2-ethylhexyl methacrylate

\section{Introduction}

In many branches of the polymer industry, the poly(alkyl methacrylates) based on the commercially available methacrylate monomers, methyl methacrylate, butyl methacrylate, and 2-ethylhexyl methacrylate play crucial

Z. Czech $(\square) \cdot$ K. Agnieszka $\cdot$ P. Ragańska $\cdot$ A. Antosik Institute of Chemical Organic Technology, West Pomeranian University of Technology, Szczecin, Pułaskiego 10,

70-322 Szczecin, Poland

e-mail: psa_czech@wp.pl roles as materials for the manufacture of glass polymers, polymeric films, paint varnishes, sealants, coatings, and diverse kinds of adhesives that are used in modern technological processes. Poly(alkyl methacrylates) are produced in the form of solvent-based, water-borne (dispersions), or solvent-free systems. Their properties depend particularly on the type of alkyl group in the side chain. Chain branching enhances hardness, while chain elongation increases plasticization [1]. These polymers display several unique properties, such as extremely good weather and aging resistance, non-yellowing, low permeability of oxygen, and good plasticizer resistance. Their major advantages are photostability and resistance to hydrolysis. The thermal decomposition of methacrylic polymers is significant because of the deterioration of these properties during high-temperature processing [2].

Pyrolysis-gas chromatography (Py-GC) can be used to easily, rapidly, and inexpensively characterize the formulations of polymers and compounded polymeric materials $[3,4]$. Under appropriate conditions, this method can be used to transform waste into useful products. In the case of polymer products, especially acrylics and methacrylics, it is possible to regenerate the monomers, which can be used to prepare degradable polymers [5-7]. The use of pyrolysis coupled with gas chromatography also enables the identification of materials under investigation, which is vital in the case of complaints [8,9].

\section{Experimental}

Materials (synthesis and characterization)

The syntheses of poly(methyl methacrylates), poly(butyl methacrylates), and poly(2-ethylhexyl methacrylates) using 
Table 1 Viscosities, molecular weights, and polydispersities of the poly(methyl methacrylates)

\begin{tabular}{lcccc}
\hline AIBN/Mass\% & Viscosity/Pa s & $\overline{\mathrm{M}}_{\mathrm{w}} / \mathrm{g} \mathrm{mol}^{-1}$ & $\overline{\mathrm{M}}_{\mathrm{n}} / \mathrm{g} \mathrm{mol}^{-1}$ & $\mathrm{P}_{\mathrm{d}} \frac{\overline{\mathrm{M}}_{\mathrm{w}}}{\overline{\mathrm{M}}_{\mathrm{n}}}$ \\
\hline 0.1 & 20.6 & 991,000 & 583,000 & 1.7 \\
0.2 & 15.1 & 901,000 & 409,000 & 2.2 \\
0.3 & 12.6 & 547,000 & 189,000 & 2.9 \\
0.4 & 9.8 & 362,000 & 91,000 & 4.0 \\
0.5 & 4.2 & 183,000 & 34,000 & 5.4 \\
\hline
\end{tabular}

the corresponding methacrylate monomers were conducted with 50 mass\% polymer content in ethyl acetate at approximately $78{ }^{\circ} \mathrm{C}$ in the presence of various concentrations of the radical initiator AIBN (2,2'-azo-bis-diisobutyronitrile) with a dosage time for the monomers of $1 \mathrm{~h}$ and a post-reaction time of $5 \mathrm{~h}$. All the monomers, polymerization media, and the radical initiator were obtained from BASF (Germany).

The viscosities of the synthesized poly(alkyl methacrylates) were determined at room temperature using a Rheomat RM viscometer (Rheometric Scientific) with a $\mathrm{nr} 3$ spindle (Table 1). The molecular weights were determined with liquid chromatography (LaChrom: RI Detector Li7490 and LaChrom UV Detector L-7400 supplied by Merck Hitachi and a PLgel $10^{6}$ Hewlett-Packard column) (Table 1).

The synthesized solvent-borne homopolymers were dried for $10 \mathrm{~min}$ at $110{ }^{\circ} \mathrm{C}$ in a drying canal on silicon paper. After drying, the thermal stabilities of the solventfree polymer films were tested. Lastly, the polymer films were pyrolyzed and the resulting pyrolysis products were examined with gas chromatography.

\section{Thermal stability}

The polymers' stabilities were assessed with thermogravimetry (TG) using a TGA 2950 unit interfaced with a Thermal Analyst 2,100 control unit from TA Instruments Inc. Each sample (approximately $5 \mathrm{mg}$ ) was placed in a platinum sample pan, and the TG cell was swept with nitrogen at a rate of $50 \mathrm{~mL} \mathrm{~min}{ }^{-1}$ during the degradation run. The temperature was ramped at $5{ }^{\circ} \mathrm{C} \mathrm{min}{ }^{-1}$ in the range $200-400{ }^{\circ} \mathrm{C}$.

\section{Degradation procedure}

Quantitative and qualitative analyses were conducted using the following gas chromatography methods. The determination of liquid products was conducted with an external standard method with the following equipment and analytical conditions: ThermoScientific $\mathrm{GC} 8000^{\mathrm{Top}}$ gas chromatograph, RESTEK RTX-5 $30 \mathrm{~m} \times 0.53 \mathrm{~mm}$ capillary
Table 2 Viscosities, molecular weights, and polydispersities of the poly(butyl methacrylates)

\begin{tabular}{lcccc}
\hline AIBN/Mass\% & Viscosity/Pa s & $\overline{\mathrm{M}}_{\mathrm{w}} / \mathrm{g} \mathrm{mol}^{-1}$ & $\overline{\mathrm{M}}_{\mathrm{n}} / \mathrm{g} \mathrm{mol}^{-1}$ & $\mathrm{P}_{\mathrm{d}} \overline{\mathrm{M}}_{\mathrm{w}}$ \\
\hline 0.1 & 17.4 & 923,000 & 486,000 & 1.9 \\
0.2 & 13.2 & 762,000 & 318,000 & 2.4 \\
0.3 & 9.9 & 485,000 & 152,000 & 3.2 \\
0.4 & 8.3 & 303,000 & 69,000 & 4.4 \\
0.5 & 2.7 & 158,000 & 26,000 & 6.0 \\
\hline
\end{tabular}

Table 3 Viscosities, molecular weights, and polydispersities of the poly(2-ethyhexyl methacrylates)

\begin{tabular}{|c|c|c|c|c|}
\hline AIBN/Mass\% & Viscosity/Pa s & $\overline{\mathrm{M}}_{\mathrm{w}} / \mathrm{g} \mathrm{mol}^{-1}$ & $\overline{\mathrm{M}}_{\mathrm{n}} / \mathrm{g} \mathrm{mol}^{-1}$ & $\mathrm{P}_{\mathrm{d}} \frac{\overline{\mathrm{M}}_{\mathrm{w}}}{\mathrm{M}_{\mathrm{n}}}$ \\
\hline 0.1 & 14.8 & 852,000 & 406,000 & 2.1 \\
\hline 0.2 & 11.9 & 691,000 & 247,000 & 2.8 \\
\hline 0.3 & 8.7 & 403,000 & 103,000 & 3.9 \\
\hline 0.4 & 6.1 & 251,000 & 48,000 & 5.2 \\
\hline 0.5 & 1.9 & 112,000 & 15,000 & 7.3 \\
\hline
\end{tabular}

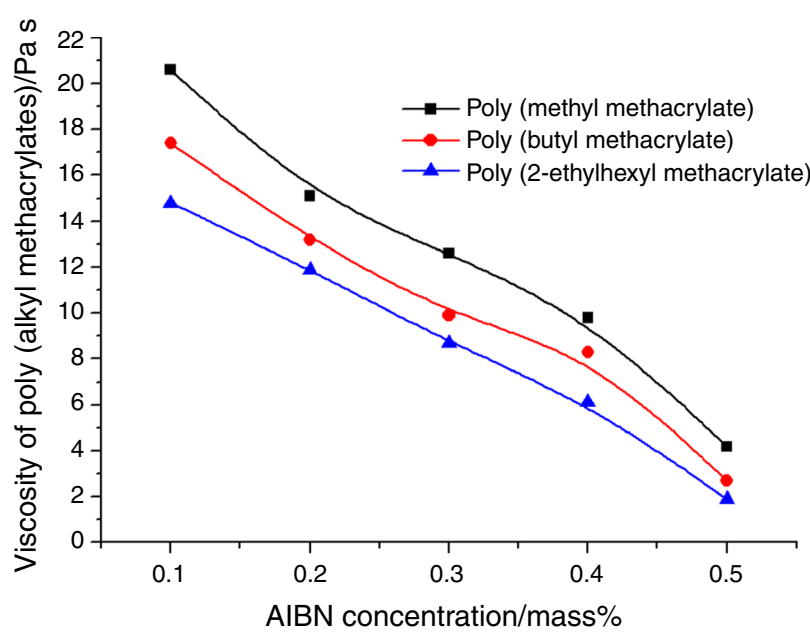

Fig. 1 The variations with AIBN concentration of the viscosities of the synthesized poly(alkyl methacrylates)

column, $1.5 \mu \mathrm{m}$ film, carrier gas $5 \mathrm{~cm}^{3} \mathrm{~min}^{-1} \mathrm{He}$, detector temperature (FID) $300{ }^{\circ} \mathrm{C}$, injector temperature $280{ }^{\circ} \mathrm{C}$ (split 1:2), oven-temperature program $45^{\circ} \mathrm{C}(4 \mathrm{~min})$ to $420{ }^{\circ} \mathrm{C}$ at $10{ }^{\circ} \mathrm{C} \mathrm{min}^{-1}$. The determination of gaseous products was conducted with an external standard method with the following equipment and analytical conditions: ThermoScientific TraceUltra gas chromatograph, ShinCarbon ST 100/120 $1 \mathrm{~m} \times 0.95 \mathrm{~mm}$ micropacked column, carrier gas $8 \mathrm{~cm}^{3} \mathrm{~min}^{-1} \mathrm{He}$, detector temperature (TCD) $200{ }^{\circ} \mathrm{C}$, injector temperature $100{ }^{\circ} \mathrm{C}$, oven-temperature program $45^{\circ} \mathrm{C}(10 \mathrm{~min})$ to $250{ }^{\circ} \mathrm{C}$ at $10{ }^{\circ} \mathrm{C} \mathrm{min}^{-1}$. 


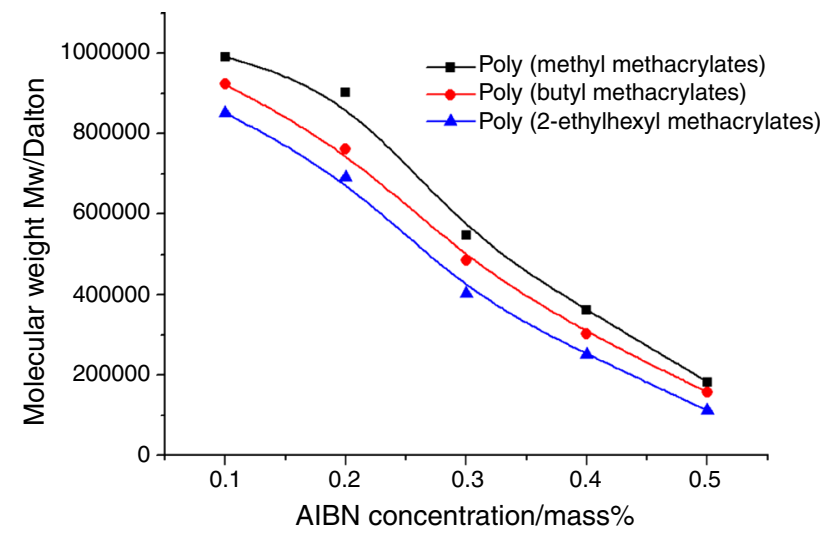

Fig. 2 The variations with AIBN concentration in the molecular weights of the synthesized poly(alkyl methacrylates)

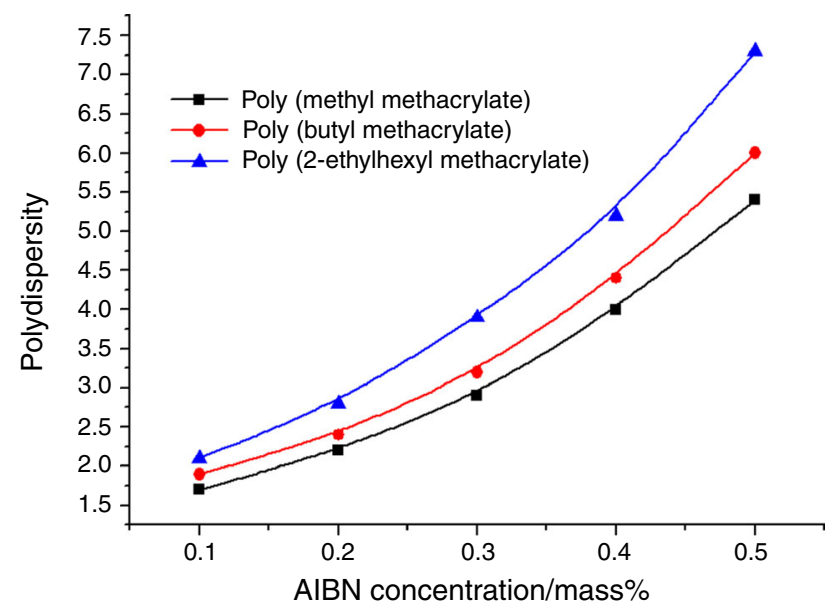

Fig. 3 The variations with AIBN concentration in the polydispersities of the synthesized poly(alkyl methacrylates)

\section{Results and discussion}

Viscosities, molecular weights, and polydispersities of the synthesized homopolymers

The variations of the viscosities, molecular weights, and polydispersities of the synthesized poly(alkyl methacrylates) with the AIBN concentration are reported in Tables 1-3 and illustrated in Figs. 1 and 2.

The results for the effects of varying the concentration of the thermal radical initiator AIBN on the viscosities of the synthesized selected poly(alkyl methacrylates) show that increasing the AIBN concentration reduces their viscosities (Fig. 1). This trend arises because when there are more free radicals available during polymerization, shorter polymer chains are formed and so the viscosity decreases. This effect also governs the trend in the average molecular

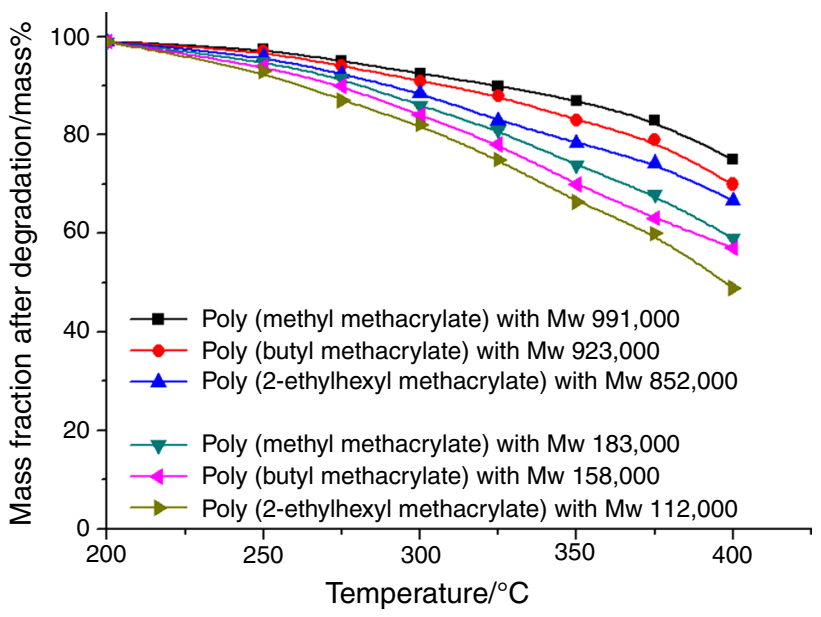

Fig. 4 Thermal stabilities of poly(alkyl methacrylates) with various molecular weights $\mathrm{Mw}$

weights, which rapidly decrease with increase in the concentration of the radical initiator (Fig. 2). In contrast, increasing the AIBN content results in poly(alkyl methacrylates) with higher polydispersities (Fig. 3). The increases in the dispersities of the poly(alkyl methacrylates) are due to the significant increases in the proportions of the polymer fractions with lower molecular weights, that is, in those fractions with shorter chain lengths.

Thermal stability

The stabilities of the synthesized poly(alkyl methacrylates) were determined with thermo-gravimetric analysis at temperatures in the range of $200-400{ }^{\circ} \mathrm{C}$. Figure 4 shows the thermal degradation characteristics of poly(alkyl methacrylates) synthesized with various molecular weights.

The thermal stabilities of poly(methyl methacrylates), poly(butyl methacrylates), and poly(2-ethylhexyl methacrylates) synthesized with various molecular weights are shown in Fig. 4. As can readily be seen, the rate of thermal degradation for the poly(2-ethylhexyl methacrylates) is much higher than that for the poly(methyl methacrylates). Higher molecular weight poly(alkyl methacrylates) have greater thermal resistance.

Thermal degradation of the poly(alkyl methacrylates)

The thermal degradation products of the poly(alkyl methacrylate) homopolymers based on methyl methacrylate, butyl methacrylate, and 2-ethylhexyl methacrylate in the temperature range $250-400{ }^{\circ} \mathrm{C}$ are listed in Table 4 , which also shows the concentrations of the breakdown products as a function of the pyrolysis temperature. The thermal degradation trials were conducted for the methacrylic 
Table 4 Breakdown products of the thermal degradations of selected poly(alkyl methacrylates)

\begin{tabular}{lrrrrrr}
\hline Pyrolysis products & \multicolumn{7}{c}{ Pyrolysis temperature $/{ }^{\circ} \mathrm{C}$} \\
\cline { 2 - 7 } & 250 & 300 & 325 & 350 & 375 & 400 \\
\hline $\begin{array}{l}\text { Concentration of breakdown products Mass\% } \\
\text { Methyl methacrylate }\left(\mathrm{M}_{\mathrm{W}}:\right.\end{array}$ & 99.8 & 99.4 & 97.7 & 96.5 & 95.0 & 93.1 \\
$\quad \begin{array}{l}\left.\text { 991,000 } \mathrm{g} \mathrm{mol}^{-1}\right) \\
\text { Others }\end{array}$ & 0.2 & 0.6 & 2.3 & 3.5 & 5.0 & 6.9 \\
$\begin{array}{l}\text { Methyl methacrylate }\left(\mathrm{M}_{\mathrm{W}}:\right. \\
\left.\text { 183,000 } \mathrm{g} \mathrm{mol}^{-1}\right)\end{array}$ & 99.9 & 99.6 & 98.5 & 97.6 & 96.6 & 95.3 \\
$\begin{array}{l}\text { Others } \\
\text { 2-Ethylhexyl methacrylate } \\
\left(\mathrm{M}_{\mathrm{W}}: 852,000 \mathrm{~g} \mathrm{~mol}^{-1}\right)\end{array}$ & 99.6 & 99.1 & 97.2 & 95.9 & 94.1 & 92.0 \\
$\begin{array}{l}\text { Others } \\
\text { 2-Ethylhexyl methacrylate } \\
\left(\mathrm{M}_{\mathrm{W}}: 112,000 \mathrm{~g} \mathrm{~mol}^{-1}\right)\end{array}$ & 99.7 & 99.3 & 98.1 & 96.8 & 95.4 & 93.8 \\
Others & 0.3 & 0.7 & 1.9 & 3.2 & 4.6 & 6.2 \\
\hline
\end{tabular}

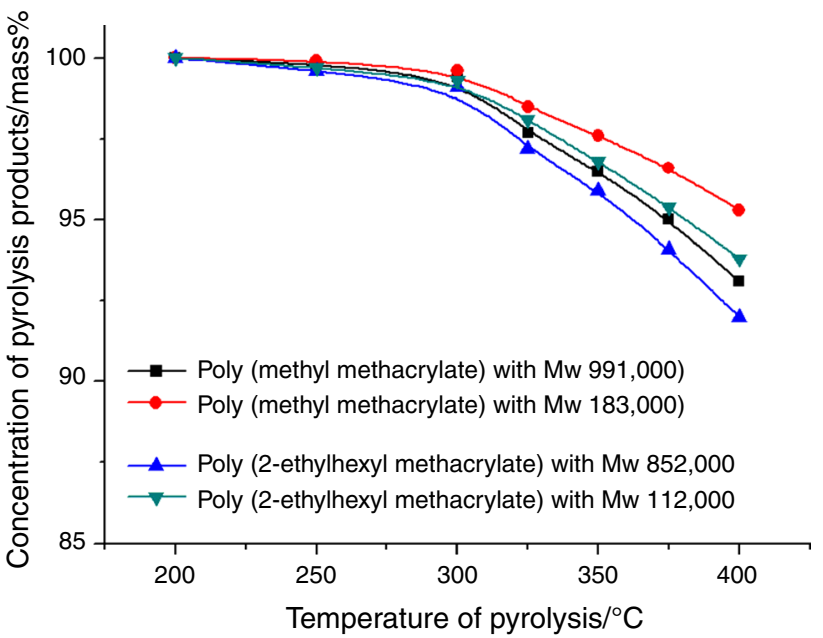

Fig. 5 Concentrations of the methacrylate monomers in the pyrolysis products

homopolymers with the highest and lowest molecular weights. At lower temperatures, the polymers degrade nearly completely to the alkyl methacrylate monomers. Other breakdown products, such as carbon monoxide, carbon dioxide, ethane, methanol, ethanol, and 1-propanol appear in only small quantities. At higher temperatures, the homopolymers based on methyl, butyl, or 2-ethylhexyl methacrylates decrease slowly, while the gas component evolution simultaneously increases.

As presented in Table 4, the concentration of methyl methacrylate in the thermal degradation by-products of a poly(methyl methacrylate) with a molecular weight of $991,000 \mathrm{~g} \mathrm{~mol}^{-1}$ drops from 99.8 to 93.1 mass\% methyl

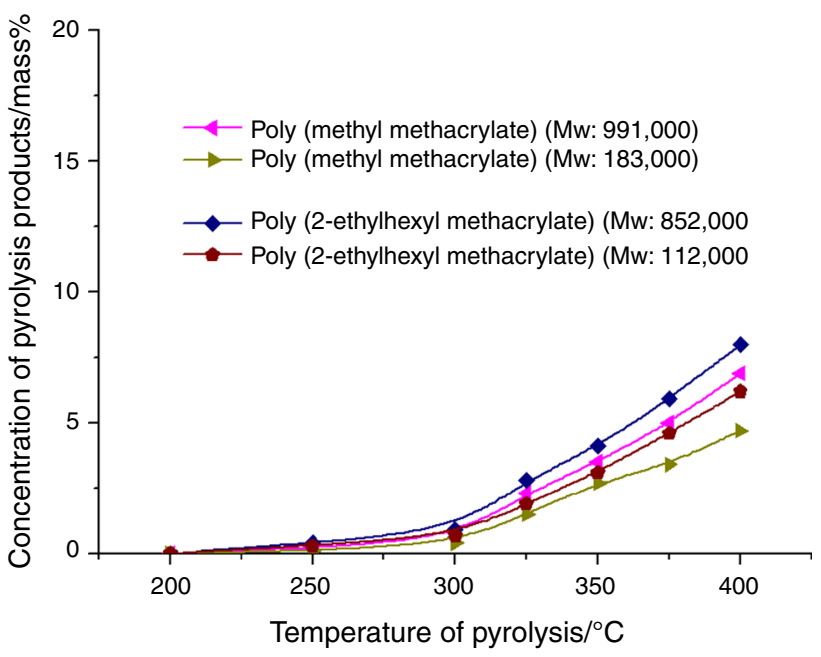

Fig. 6 Concentrations of other pyrolysis products

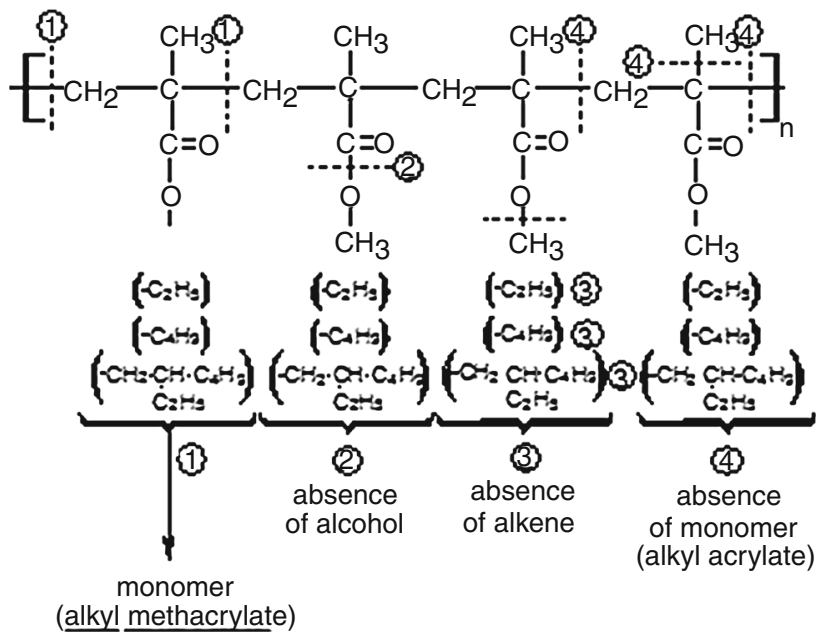

Fig. 7 Thermal degradation scheme for the poly(alky1 methacrylates)

methacrylate when the temperature is increased from 250 to $400{ }^{\circ} \mathrm{C}$. For this temperature increase, the concentration of 2-ethylhexyl methacrylate in the thermal degradation byproducts of poly(2-ethylhexyl methacrylate) with a molecular weight of $852,000 \mathrm{~g} \mathrm{~mol}^{-1}$ drops from 99.6 to 92.0 mass\% (Fig. 5). The concentrations of other thermal degradation products such as carbon monoxide, carbon dioxide, ethane, methanol, ethanol, and 1-propanol are very low and increase continuously (Fig. 6).

The main difference between the thermal degradations of acrylic and methacrylic polymers is the large yield of monomers in the case of methacrylic polymers. In the conducted pyrolysis experiments, the methacrylate monomers account for 92-99.8 mass\% of the total yield (Table 4). This result is not surprising because the thermal 
degradation of poly(methyl methacrylate) is essentially the reverse of its polymerization, which leads to methyl methacrylate monomer in the yield of nearly $100 \%$. It was confirmed for all the tested poly(alkyl methacrylates) that the corresponding methacrylate monomers, that is, methyl methacrylate, butyl methacrylate, and 2-ethylhexyl methacrylate, are the genuine thermal degradation products. Thus, the thermal degradations of poly(alkyl methacrylates) are depolymerization processes. In contrast, the typical breakdown products of poly(alkyl acrylates) are alkenes, long chain alcohols, and acrylate monomers. The diffusion of degradation products also plays an important role in the thermal degradation of acrylic polymers. Most important are the degradation conditions, especially the temperature of pyrolysis. After homolysis of the chain, the macroradicals depropagate with a very long zip length, so that chains with a sufficiently low degree of polymerization unzip completely. This mechanism leads to the absence of dimer, trimer, and other by-products deriving from random main-chain scission from the poly(alkyl methacrylates) degradation products (Fig. 7).

The principal degradation products of poly(alkyl methacrylates) are accordingly the monomers used in the polymerization process, and in the temperature range of interest the amounts of monomer formed (only methacrylates) according to process (1) are strongly dependent on the pyrolysis temperature. The formation of energetically less favorable primary carbon radicals leads to methacrylate evolution.

The quantitative results reveal the dependencies of the monomer yields on the number of carbon atoms in the alkyl side chains. The concentration of short alkyl side-chain monomers (methyl) is higher than those of long side-chain monomers (butyl, 2-ethylhexyl): in other words, the longer the alkyl side chains in the poly(alkyl methacrylates), the fewer monomers are formed during pyrolysis. During cracking, especially at higher temperatures, gaseous products and mixtures of low molecular weight alcohols are formed (Fig. 6).

\section{Conclusions}

A simple degradation mechanism provides a satisfactory explanation for the results of this study for the thermal degradations of poly(alkyl methacrylates) in the temperature range $200-400{ }^{\circ} \mathrm{C}$, and in particular for the formation of the major pyrolysis products, which are methyl methacrylate, butyl methacrylate, and 2-ethylhexyl methacrylate. The general mechanism of the thermal degradations of the poly(alkyl methacrylates) consists of random main-chain scission reactions. The predominant degradation products of poly(alkyl methacrylates) under the investigated pyrolysis conditions between 200 and $400{ }^{\circ} \mathrm{C}$ are methacrylate monomers. Thus, this process is ideal for the recycling of methacrylic polymer waste and the recovery of methacrylate monomers.

Open Access This article is distributed under the terms of the Creative Commons Attribution License which permits any use, distribution, and reproduction in any medium, provided the original author(s) and the source are credited.

\section{References}

1. Czech Z, Loclair H. Solvent-based pressure-sensitive adhesives for removable products. Int J Adhes Adhes. 2006;26:4-418.

2. Bertini F, Audiso G, Zuev VV. Investifation of the thermal degradation of poly-n-alkyl acrylates and poly-n-alkyl methacrylate $\left(\mathrm{C}_{1}-\mathrm{C}_{12}\right)$. Polym Degrad Stab. 2005;89:2-239.

3. Wang F, Burleson A. The development of pyrolysis-fast gas chromatography for analysis of synthetic polymers. J Chromatogr A. 1999;833:1111-9.

4. Zuev VV, Bertini F, Audisio G. Polym Degrad Stab. 2000;69:169-74.

5. Czech Z, Pełech R. The thermal degradation of acrylic pressuresensitive adhesives based on butyl acrylate and acrylic acid. Prog Org Coat. 2009;65:84-7.

6. Czech Z, Pełech R. Thermal degradation of butyl acrylate-methyl acrylate-acrylic acid-copolymers. J Therm Anal Cal. 2009;96:583-6.

7. Czech Z, Pełech R. Thermal degradation of solvent-borne watersoluble acrylic acid-butyl acrylate-copolymers. Mater Sci Pol. 2009;2:851-6.

8. Germinario L, Shang P. Advances in nano thermal analysis of coatings. J Therm Anal Cal. 2008;1:207-11.

9. Czech Z, Pełech R. J Therm Anal Cal. 2010;101:309-13. 